Revista de la red interuniversitaria de estudios sobre las literaturas rioplatenses contemporáneas en Francia

Hors-série | 2019

Ricardo Piglia: Cierta idea de literatura

\title{
De la literatura, el pudor y la verdad. Sobre Ricardo Piglia
}

\section{Adriana Rodríguez Pérsico}

\section{OpenEdition}

\section{Journals}

Edición electrónica

URL: http://journals.openedition.org/lirico/7899

DOI: $10.4000 /$ lirico.7899

ISSN: 2262-8339

Editor

Réseau interuniversitaire d'étude des littératures contemporaines du Río de la Plata

\section{Referencia electrónica}

Adriana Rodríguez Pérsico, « De la literatura, el pudor y la verdad. Sobre Ricardo Piglia », Cuadernos LIRICO [En línea], Hors-série | 2019, Puesto en línea el 11 febrero 2019, consultado el 09 mayo 2019 URL : http://journals.openedition.org/lirico/7899 ; DOI : 10.4000/lirico.7899

Este documento fue generado automáticamente el 9 mayo 2019.

\section{(c) $(1) \ominus$}

Cuadernos LIRICO está distribuido bajo una Licencia Creative Commons Atribución-NoComercialSinDerivar 4.0 Internacional. 


\title{
De la literatura, el pudor y la verdad. Sobre Ricardo Piglia
}

\author{
Adriana Rodríguez Pérsico
}

\section{El libro}

1 "Le monde est fait por aboutir à un beau livre". Con estas palabras termina la entrevista realizada por Jules Huret a Mallarmé, en 1891, para L' Echo de Paris. En el caso de Ricardo Piglia, Los diarios de Emilio Renzi son ese bello libro en el que desemboca una fértil trayectoria. Los últimos años de su vida -tal vez como modo de conjurar la enfermedadPiglia se abocó a la transcripción de los diarios donde, desde la adolescencia, anotó experiencias literarias, amistosas, familiares, amorosas, educativas y políticas. Son trescientos veintisiete cuadernos marca Congreso y Triunfo que componen sus "archivos personales". Con esta insistencia, Piglia se hizo un cuerpo de escritura que le funcionó como antídoto; se construyó un cuerpo allí donde lo real lo recluía al organismo.

2 Los diarios de Emilio Renzi abarcan tres volúmenes que llevan por subtítulos: Años de formación (2015), Los años felices (2016) y Un día en la vida (2017). Son la recapitulación lúcida de vida y obra fusionadas al punto que no se distinguen entre sí y una toma sentido por la otra. Se vive por y en la literatura. Pero lejos de apelar al espontaneísmo fácil, el escritor se empeña en pensar el qué y escoger minuciosamente el cómo. Fiel a su propia tradición de traspasar fronteras y torcer reglas genéricas, la ficción autobiográfica quiebra a menudo los pactos de lectura. Los diarios no cumplen siquiera con la convención que superpone las figuras de autor y narrador: en la tapa, dos autores se hacen cargo del discurso. El cuerpo del texto alterna la primera y la tercera personas. Hablar de la propia vida como si fuera de otro. Es al otro al que le ocurren las peripecias. Borges produjo páginas magistrales sobre el desdoblamiento entre el escritor célebre y el hombre común, sujeto a los avatares del mundo cotidiano. Piglia se inclina por otro tipo de desdoblamiento involucrando a su alter ego, Emilio Renzi.

3 En su lúcido ensayo "Piglia/Renzi, postrero desliz", incluido en este volumen, Julio Premat analiza los deslizamientos entre uno y otro en los siguientes términos: 
Los últimos años, concentrados entonces prioritariamente en publicar un material de índole íntima, tuvieron un efecto tan espectacular como paradójico: en vez de acentuar el aspecto autobiográfico de su obra, pusieron de relieve la operación fabuladora más fuerte de su proyecto, a saber el desplazamiento del yo biográfico a un personaje, ese personaje de autor que se dio en llamar Emilio Renzi. Así, la escritura, en vez de dar cuenta de la vida sería, según la expresión de Piglia en Crítica y ficción, "el lugar donde los borradores de la vida son posibles" (2001: 109), es decir el lugar de esbozar o soñar una vida efímera, inestable, corregible.

En otro lugar, hablé de "pudor autobiográfico" (Rodríguez Pérsico 2017), aunque la expresión resulte un oxímoron porque nadie que quiere permanecer de incógnito sostiene semejante proyecto durante décadas. No obstante, Piglia se muestra un autobiógrafo discreto, como si siguiera a pie juntillas la frase de Blaise Pascal: "El yo es odioso". Por medio de la ausencia de voces estridentes y la elusión de sentimientos desbordados, la pasión de las ideas se declina en prosa reflexiva. Con ello, apunto a un decir que prefiere los tonos bajos mientras argumenta contra las maneras desenfrenadas.

Precisamente en una de las conversaciones en Princeton, Piglia se refiere a su estilo como "una poética de la elipsis y la distancia" (2015b: 129). Esa es la elección formal para registrar las experiencias en los diarios. No se trata de mostrar buenos modales; el tono contenido envuelve una cuestión de preferencias poéticas, ya sea que se describan vicios privados, amores contrariados, éxitos editoriales, relaciones amistosas, estrecheces económicas o los signos de la enfermedad. Y en esto, Piglia se acerca a Borges al punto que en Los años felices un fragmento de "Indagación de la palabra" opera como faro: "El sujeto es casi gramatical y así lo anuncio para aviso de aquellos lectores que han censurado (con intención de amistad) mis gramatiquerías y que solicitan de mí una obra humana". Para concluir ratificando al maestro en aquello de "lo más humano es la gramática" (Piglia 2016: 68). Así lo corroboran incluso los momentos tremendos que anuncian la enfermedad:

Ellos pensarán que no es una metáfora y que cuando digo "Vivo en el cuerpo de otro" es así, tal cual, son literales, se toman todo al pie de la letra, por eso quiero decir que tengo la sensación de que mi cuerpo no me obedece, que yo estoy sano, lúcido, para decirlo así, pero mi cuerpo está averiado. Nada grave, no hay que alarmarse, les digo a mis amigos. Soy un herido de guerra, un veterano [...] (2015a: 344).

6 La prosa se construye sobre la base de una heterogeneidad radical donde entran materiales diversos y múltiples estrategias narrativas: repeticiones temáticas, saltos y elisiones temporales, inclusión de listas cotidianas, conversaciones triviales, cuentos, reflexiones estéticas y políticas, comentarios de libros escritos y leídos, encuentros amistosos y eróticos, conflictos entre trabajo y dinero, relaciones entre familia y relato. A lo largo de los volúmenes, numerosas intervenciones desbaratan las cronologías de modo que Renzi es a veces un joven pletórico y otras, un hombre viejo y enfermo: "mis cuadernos son para mí la máquina del tiempo [...] Paso de una época a otra, al azar, tengo los cuadernos guardados en cajas de cartón, sin indicación de fechas ni de lugar" (2015a: 358). Los diarios siguen la lógica del inconsciente donde no hay tiempo $\mathrm{y}$, por consiguiente, tampoco muerte. El inconsciente es atemporal y no posee representación de la muerte. Allí, todo es posible y sin contradicción. Como si la continuidad de la escritura en su misma dispersión asegurara la continuidad de la vida.

7 Un ejemplo. La primera parte del tomo tercero que se titula "Los años de la peste" -lapso de la dictadura cívico-militar- termina con el apartado "Los finales" que enhebraban una serie de reflexiones y afecciones deslizadas casi por azar. Vida y literatura se solapan, se 
implican y se entrecruzan. Piglia se ocupó intensamente de analizar sentidos y formas de finales en la literatura; en este momento, los finales tienen que ver con la terminación de la escritura de los diarios y con el final de su vida. "Los finales" es un fragmento de vejez que ensambla cuestiones literarias, el ocaso de una existencia singular y de ciertos patrones generacionales. Un narrador en tercera persona saca conclusiones:

Se había terminado una época en la que una realidad mejor era posible, una época en la que él y sus amigos vivían en una sociedad paralela, un mundo propio, ajeno a la corriente principal de la cultura argentina. Habían vencido porque seguían vivos y combatían, pero también habían sido derrotados, tenían en el cuerpo las cicatrices y las marcas, eran sobrevivientes, eran heridos de guerra. Las ilusiones eran ahora, subrayó, más ilusas que nunca, pero la vida social y política era ahora más benigna que nunca (2017: 159) ${ }^{1}$.

Renzi cita los casos de Saer, Borges, Puig y Arlt heridos y muertos -aniquilados quizáscomo consecuencia de haber estado sometidos a la incandescencia del lenguaje, "al brillo inigualable de la lengua argentina" (2017: 158). En la charla con su médico, Renzi le habla de sus cuadernos, "de los años que pasé expuesto al brillo perturbador de la lengua materna". El médico le aconseja abandonarlos para hacer una vida sana. Nadie sale indemne de la experiencia literaria; más aún, la perseverancia conduce de modo inevitable a la destrucción. Renzi decide detenerse en 1982 porque esa fecha significa el cierre de una etapa. Opta entonces por concentrar una vida en un día a la manera joyceana, aunque esto se elabore de manera peculiar porque el día se arma con múltiples fechas y acontecimientos: "Me detuve en 1982 porque hasta ahí no había abdicado ni me había suicidado, y luego, como el profeta Isaías, confundiría los años con los días, una jornada entera que encerrara, en sus horas, varios tiempos" (162). El diarista muestra sus estrategias discursivas al desentenderse de cronologías de almanaque mientras resalta la capacidad de la narración para seleccionar de entre todos los recuerdos aquellos que configuren una trama perfecta.

La pregunta que abre el último párrafo evoca la que inicia Respiración artificial y, de algún modo, responde a ella. Si en la novela de 1980 se interrogaba por un pasado inmediato contenido en la pregunta " $¿$ Hay una historia?”, en este momento se dirige al futuro próximo: “¿Había un final?” (2017: 162). El final escogido no es el del personaje de Faulkner Quentin Compson que se suicida ni el de Alonso Quijano que recupera la cordura. Su método de resistencia fue la práctica literaria y mantenerse vivo hasta asegurarse de que los diarios saldrían de la imprenta. La elipsis y la distancia son recursos cruciales en este proceso.

10 Hay un pequeño ensayo en el que Piglia desarrolla esta voluntad de distanciamiento en prosa bella y eficaz. "Una propuesta para el próximo milenio" se publica originariamente en una revista cultural en San Pablo y luego se incluye en la Antología personal de 2014, lo que muestra la importancia que su autor le daba en la medida en que el género presupone gusto íntimo o afición intelectual por determinados escritos². El texto se recorta sobre "Seis propuestas para el próximo milenio" que Ítalo Calvino pergeñara años antes, en 1985. Allí, despliega los aspectos, los rasgos que la literatura del 2000 debía preservar: levedad, rapidez, exactitud, visibilidad, multiplicidad. Calvino alcanzó a redactar cinco. Ya en el comienzo de milenio, Piglia completa la tarea elaborando la sexta propuesta, pensada "desde este suburbio del mundo” que es Buenos Aires: “¿Cómo se verían el futuro de la literatura o la literatura del futuro, desde el margen, en la periferia de las tradiciones centrales, mirando al sesgo?" (2014: 119). 
11 Piglia retoma el gesto de Borges cuando imagina que el aleph -la totalidad concentrada en un punto- se encuentra en el sótano de una casa común de un modesto barrio porteño y con ello emplaza el absoluto en un espacio lateral. Desde similar posición marginal, Piglia se atreve a imaginar una forma posible de la literatura futura a partir de una pregunta que, un sinfín de veces, se han hecho los escritores: ¿cómo narrar el horror? La respuesta consiste en un desplazamiento, un deslizamiento de la posición enunciativa, un cambio de lugar porque se le cede al otro: "Salir del centro, dejar que el lenguaje hable también en el borde, en lo que se oye, en lo que llega de otro" (2014: 123).

El escritor busca en el cantero de la literatura nacional y escoge la figura y la obra de Rodolfo Walsh quien "llevó al límite la noción de responsabilidad civil del intelectual" (2014: 120) hasta entregar la vida. Walsh tenía un estilo conciso y concentrado y cultivaba ritmos y tonos de la oralidad. Escritor, militante político, periodista, investigador sagaz, Walsh fue secuestrado y asesinado por el ejército argentino en marzo de 1977. Piglia matiza la pregunta inicial sustituyendo horror por dolor y toma la "Carta a Vicky", la hija guerrillera que muere en un enfrentamiento con el ejército. Se detiene en un pasaje: "Hoy en el tren un hombre decía 'Sufro mucho, quisiera acostarme a dormir y despertarme dentro de un año'”. Y luego: “Hablaba por él pero también por mí" (2014: 121). Modo sobrio y conmovedor, dice, de hablar del dolor propio. Para contar una experiencia límite, Walsh introduce un personaje en cuya boca pone la desesperación. Poco importa que el hombre exista o sea un personaje inventado; interesa que puede narrar "el punto ciego de la experiencia" (2014: 122). Una manera de habitar el recato.

Otros pasajes extraídos de la "Carta a mis amigos" y Operación masacre refuerzan la idea de que darle la voz a otro es la forma adecuada para contar lo que resulta casi indecible. No alcanza con recurrir al célebre procedimiento del extrañamiento o la ostranenie que estudiaron los formalistas rusos. Piglia corrige su argumentación haciéndola más contundente: se trata de poner a otro en el lugar propio, de transferir la experiencia, de desplazar la fuente de enunciación: "La verdad tiene la estructura de una ficción donde otro habla. Hay que hacer en el lenguaje un lugar para que el otro pueda hablar" (2014: 24). Se trata -podríamos agregar- de un otro en sentido bajtiniano. Un otro que es mi semejante, o quizás mi prójimo, y por eso puede tomar mi lugar haciéndose cargo de la palabra doliente. Ese otro se responsabiliza conmigo y por mí, aunque el lenguaje no pueda cubrir la totalidad de lo real porque siempre hay una falta, una carencia.

El ensayo termina aproximando a Walsh y Bertolt Brecht por el trabajo con el lenguaje y la conciencia del estilo. Piglia cita un pasaje de "Cinco dificultades para escribir la verdad": "Tener el valor de escribirla, la perspicacia de descubrirla, el arte de hacerla manejable, la inteligencia de elegir a los destinatarios. Y sobre todo, la astucia de saber difundirla" (2014: 128). Leemos en Brecht que la verdad tiene un tono que encontramos únicamente en la radicalidad de la lucha:

Para los que escriben es importante encontrar el tono de la verdad. Por lo regular se oye por ahí un tono suave, quejumbroso, el de las gentes que no son capaces de matar una mosca. El que escucha este tono y está en la miseria, se hace más miserable. Así hablan algunos que quizá no son enemigos, pero indudablemente no son compañeros de lucha.

La verdad es algo belicoso, no combate únicamente la falsedad, sino también a determinadas personas que la difunden. (2016 Web)

Según Piglia, las cinco dificultades y la propuesta esbozan la esperanza de una literatura futura. Las reflexiones finales encajan en su concepción de la literatura como un espacio donde la verdad puede ser dicha, pasando de lo latente a lo manifiesto. La sexta propuesta 
articula el tono necesario: el desplazamiento pronominal, el pudor, la contención son formas del distanciamiento que convienen a tal fin.

\section{La memoria, el olvido, la verdad}

En vez de ceder a la adversidad, Piglia optó por intervenir y publicar su última gran obra. Con tono burlón, el narrador - o los narradores, puesto que se alternan una primera y una tercera persona- asegura: “[...] ya que no había podido aprender el arte de olvidar, pese a que había hecho los ejercicios rusos destinados a construir el olvido voluntario de los hechos de su vida, entonces, iba a concentrar su energía en un punto, en un momento casi sin tiempo, dieciocho horas, digamos de mi vida [...]" (2017: 162). Ese punto origina la utopía de un mundo donde el tiempo no pasa y por lo tanto, la vida solo cesa cuando la escritura termina.

Los hechos y su rememoración son heterogéneos. Cuando recordamos, ponemos en marcha un trabajo de selección e interpretación, una traducción en imágenes y en palabras que implican siempre algún tipo de pérdida respecto de los acontecimientos o las vivencias, impresiones o afectos originales. De lo contrario, viviríamos el mismo drama del personaje del cuento de Borges, "Funes el memorioso", que recordaba cada detalle sin distinguir lo valioso de lo nimio.

En su monumental La memoria, la historia, el olvido, Paul Ricoeur hace hincapié en los significados de las palabras griegas mneme y anamnesis: la primera se refiere a un recuerdo que aparece de improviso, que sobreviene a la manera de una afección, la segunda lo concibe como producto de una búsqueda activa. Buscar es esperar encontrar, dice Ricoeur (2004: 556). Y encontrar es reconocer lo que una vez se aprendió. En el trabajo de rememoración, el camino va del “¿qué?" al “¿quién?" para culminar en el “¿cómo?”. También recurre a Aristóteles para subrayar el carácter siempre pretérito de la memoria.

19 Acaso la memoria voluntaria pretenda atesorar rastros de algo pasado que, siendo fragmentario, sirva para reconstruir una escena entera. La huella o el rastro es el resto significante, materialidad presente de algo ausente. El que recuerda hace un trabajo de anagnórisis o de reconocimiento por el cual una imagen vuelve a aparecer. En esa dirección, los diarios funcionan como pequeños testimonios dispersos y parciales de una totalidad clausurada. El que ha sido o lo que ha sido adquiere una significación positiva frente a lo que ya no se es o ya no es. Por eso, el texto esquiva la mirada melancólica y el dejo nostálgico para erigirse en documento de una vida que se despliega en momentos determinados y en lugares concretos. Como "Martín Fierro que canta para no olvidar", Piglia (Renzi) se construye un lugar en la historia de la literatura. Escribe para que la historia no lo olvide ni olvide que existen esos modos jubilosos de vivir la pulsión.

El contenido de "Un día en la vida" contradice al propio título. Piglia amalgama tiempos concentrándolos según sus sentidos: se alude al período alfonsinista, hay fragmentos de diarios de 1987, se cuentan un episodio de amistad de 1990 en Estados Unidos, anécdotas de infancia con la prima Erica y también de la relación actual con ella, se hace referencia a hechos sucedidos durante el gobierno menemista (como la instalación de la carpa blanca de los docentes entre 1997 y 1999), se citan páginas del diario del 2000.

21 En ese fragmento que puede leerse como una nouvelle autónoma, el tema del olvido ocupa una extensión considerable. El tópico aparece en una escena en casa de Junior, donde se desarrolla una reunión de amigos. Sintiéndose culpable por la muerte de su primo, Emilio 
le describe a Junior un método para olvidar inventado por los servicios de inteligencia soviéticos: "Hay que olvidar, pensó Renzi, ésa es la salida, se dijo mientras encaraba hacia la puerta tratando de no perturbar a los oradores" (2017: 204).

Es el contexto que abre paso a una clase en la Universidad de Buenos Aires sobre el olvido en la literatura seguida por el relato de reuniones de investigación sobre el tema en las que la elaboración de sesudos conceptos culmina en modestos banquetes en bares aledaños a la facultad. Renzi subraya el carácter festivo de esos momentos que resultan de la plenitud del conocimiento, la camaradería y la complicidad que provee la literatura. En ese día en la vida, los recuerdos de los alumnos y de su equipo de trabajo adoptan el signo del entusiasmo.

Didáctico, el profesor enseña:

En esta serie quisiera retomar la noción de olvido. Hay algo olvidado porque es indescifrable o porque es incomprensible o porque alguien lo ha borrado. Pero la cuestión, para nosotros, es si el olvido puede ser deliberado y qué clase de estrategia sería ésa, qué provoca o produce un olvido, es decir, que algo sea olvidado (2017: 205).

Lo olvidado: lo borrado, lo indescifrable, lo incomprensible. Renzi persigue etimologías que logran capturar algunos sentidos densos que irradian desde los diarios hacia otros textos. De otro modo, esos sentidos sirven de puentes o articuladores. Renzi explica el significado de la palabra aletheia (verdad en griego), que refiere al "estado en el que las cosas no pertenecen al olvido, es decir, son conocidas y patentes $\mathrm{y}$, por eso, son esencialmente verdaderas" (2017: 205-206). Aletheia y lethe comparten la raíz del verbo lanthano que significa no ser manifestado, estar latente. Y como cuando algo escapa a nuestra percepción podemos equivocarnos, asegura que la memoria es una herramienta para defendernos del error: "En la tradición griega, entonces, el olvido es antagónico de la verdad y no ya de la memoria, es decir, puede ser asimilado a la construcción de un mundo ilusorio y frágil" (2017: 206). La verdad, o mejor, el lugar y las apariciones, las variaciones de la verdad pueden resultar punto de partida para la lectura.

Olvido se opone a verdad. En "La doctrina de Platón acerca de la verdad" (escrito en 1940 y publicado un par de años más tarde), Martin Heidegger analiza el mito de la caverna que desarrolla Platón en La República. La partícula privativa a- presente en aletheia cambia el sentido del vocablo para significar lo no oculto o lo desoculto. Resulta entonces que la verdad surge de un proceso de desocultamiento, -que es un modo en que adviene el ser-, de hacerse visible algo que está escondido o suprimido (o reprimido, interpretará Freud refiriéndose a los recuerdos encubridores). El filósofo subraya el carácter agonístico del proceso ya que la disimulación tiende a mantenerse. La verdad no se abre paso de manera pacífica o armoniosa. Por el contrario, "verdad significa primariamente lo arrancado con lucha a la ocultación en que yacía. De modo que verdad es ese arrancar con lucha y siempre en la forma de un desentrañar" (Heidegger 2007: 288). "Arrancar", "lucha", "desentrañar", tres términos que raramente asociamos con una idea de verdad resplandeciente, clara y definida ${ }^{3}$. El concepto adquiere un sentido conflictivo y prometeico; en él, todo es movimiento y transformación, posibilidad y ocurrencia.

En un segundo momento, Heidegger advierte en la teoría platónica un desplazamiento del significado de lo desoculto hacia lo justo y la percepción justa. Hay entonces una mutación en el sentido de verdad: "Dicha ambigüedad manifiéstase en todo su filo, por cuanto en el mismo orden de ideas se trata y se enuncia de la aléetheia, y simultáneamente es mentada la orthótees, y asentada como regla" (2007: 295). El término pasa a designar la 
exactitud de la percepción y del lenguaje. Heidegger termina el ensayo con la reivindicación del sentido primero de aletheia: la verdad no tiende a la adecuación entre palabra y cosa sino al develamiento de algo.

Conviene detenerse en esa clase de Piglia en la Facultad de Filosofía y Letras en la que se otorga un papel fundamental a la memoria como compañera de la verdad y a la idea de que "los recuerdos olvidados no desaparecen sino que son sepultados en algún lugar" (Piglia 2017: 206), en lo que Renzi llama "archivo amnésico" prefiriendo en este caso la etimología de anamnesis -el recuerdo que se encuentra a partir de una búsqueda intensaen vez de la de mneme, el recuerdo que surge de golpe, sin quererlo. A este último alude en otro momento, cuando elabora una sutil prosopopeya: "La memoria funciona de ese modo, uno pisa el pie de un recuerdo y llega el zarpazo y la sangre" (2015a: 189). De modo oblicuo y lateral, la prosa muestra la práctica selectiva del memorialista.

La literatura tiene la función de desocultamiento y por ello es verdadera en sí misma. La verdad de la ficción aparece, en Piglia, en textos tempranos. Valga como ejemplo "La loca y el relato del crimen", que escribió para un concurso literario y que resultó uno de los cinco cuentos ganadores del Primer Certamen Latinoamericano de Cuentos Policiales organizado por Siete días en 1975.

El relato se construye en torno a la dupla verdad y locura. La loca mendiga ha sido testigo de un crimen y denuncia en su discurso delirante la identidad del asesino. Angélica Inés Echevarne es un personaje que migra de un relato a otro, una especie de Casandra, iluminada y alucinada, que pregona la verdad en clave oracular ${ }^{4}$. Pero nadie la escucha. La forma del relato consiste en secuencias que se cortan, en acciones interrumpidas. El asesinato pertenece a una secuencia elidida. Cuando aparece en escena Emilio Renzi, el crimen ya ha acontecido y todos los personajes están en la trama: la víctima, el asesino, el acusado.

Renzi parece escapado de las novelas de Arlt: un intelectual, ducho en la lingüística de Trubetzkoy, escritor de bibliográficas que arrastra su melancolía en el paupérrimo campo de la literatura nacional ${ }^{5}$. Como el mismo Arlt que fue reportero de noticias policiales, el joven periodista suplanta a un compañero enfermo en la cobertura del homicidio de una prostituta. Para develar el enigma, se vale de la tecnología y la ciencia del momento. Curioso por desentrañar el caso, graba el discurso de la mendiga y usa un código para analizar el discurso psicótico ya que aún en el delirio se puede desbrozar la verdad. Descubre entonces que el asesino no es el cliente devenido macró sino un hombre mucho más poderoso que pretendía a la mujer. "El delirio está ordenado", le dice a su jefe, lo que no se repite es lo que el loco trata de filtrar a pesar de la compulsión repetitiva:

Fíjese que ella va diciendo esas palabras, las subrayadas en rojo, las va diciendo entre los agujeros que se puede hacer en medio de lo que está obligada a repetir, la historia de Bairoleto, la virgen y todo el delirio. Si se fija en las diferentes versiones va a ver que las únicas palabras que cambian de lugar son ésas con las que ella trata de contar lo que vio (Piglia 1981: 104).

Aunque da testimonio -la loca ha visto, ha sido testigo- su palabra carece de legitimidad. Renzi busca la verdad por fuera del sentido común que señala otro culpable. Ante la imposibilidad de publicar la nota vetada por el jefe de redacción que no quiere problemas con la policía, Emilio se sienta frente a la máquina de escribir pero en lugar de redactar su renuncia, comienza a narrar el caso. Describiendo un círculo perfecto, las palabras finales son idénticas a las del comienzo: "Gordo, difuso, melancólico, el traje de filafil verde nilo 
flotándole en el cuerpo -empezó a escribir Renzi-, Almada salió ensayando un aire de secreta euforia para tratar de borrar su abatimiento" (1981: 105).

Ese gesto señala el pasaje a la literatura. Renzi sale del registro periodístico de la crónica policial para entrar en el relato donde no valen las reglas ni rigen las leyes de la vida cotidiana. El relato se revela búsqueda y exposición de la verdad; se postula forma posible de saber y de hacer conocer lo que no puede decir el discurso periodístico. Para contar la verdad, escoge un espacio donde la oposición verdad-mentira está invalidada. La loca excluida de la sociedad- es quien dice la verdad mientras los cuerdos -como miembros activos de esa misma sociedad- la ignoran y hasta la menosprecian. El relato confunde las categorías de verdad y verosimilitud. Si en la vida rigen los patrones de verdad y la literatura opera con procedimientos generadores de verosimilitud, "La loca y el relato del crimen" invierte esta lógica para mostrar que la literatura tiene un saber verdadero. La verdad de la ficción no es absoluta sino contingente pero no por eso resulta menos plausible.

En una vieja entrevista de 1984, cuando le preguntaron sobre la especificidad de la ficción, Piglia explica la relación específica que la ficción mantiene con la verdad y agrega su voluntad de articular ambos términos:

Me interesa trabajar esa zona indeterminada donde se cruzan la ficción y la verdad. Antes que nada porque no hay un campo propio de la ficción. De hecho todo se puede ficcionalizar. La ficción trabaja con la creencia y en este sentido conduce a la ideología, a los modelos convencionales de realidad y por supuesto también a las convenciones que hacen verdadero (o ficticio) a un texto. La realidad está tejida de ficciones. La Argentina de estos años es un buen lugar para ver hasta qué punto el discurso del poder adquiere a menudo la forma de una ficción criminal. El discurso militar ha tenido la pretensión de ficcionalizar lo real para borrar la opresión (1990:15).

En esa oportunidad, establece diferencias entre el discurso ficcional y el discurso crítico ya que "todo el trabajo de la crítica, se podría decir, consiste en borrar la incertidumbre que define a la ficción. El crítico trata de hacer oír su voz como una voz verdadera" (1990: 18). El párrafo defenestra la ilusión de objetividad. Todo es una construcción, un "como si” y en esa dirección, podríamos decir que el trabajo de la crítica se acerca a la ficción, puesto que la ficción misma se define en esos términos. En el enunciado no hay posiciones dogmáticas. Se concibe a la crítica como una práctica que se esfuerza por alcanzar algún tipo de certeza. No se trata de una verdad única o incuestionable sino más bien de su producción. Como sostiene Alain Badiou, el arte es productor de verdad, junto con la política, el amor y la ciencia. En esos cuatro campos se produce el advenimiento de acontecimientos-verdad. El sujeto es el soporte de esas verdades:

[...] el arte es aquello que, a nivel del pensamiento, le hace justicia al acontecimiento. En política los acontecimientos son catalogados por la historia post hoc. Únicamente el arte le restituye completamente -o intenta hacerlo- su potencia intensiva. Solo el arte restituye la dimensión sensible de lo que es un encuentro, una sublevación, un motín. El arte, bajo todas sus formas, es la gran reflexión del acontecimiento en tanto tal (Badiou 2012: 76).

Darle supremacía al arte porque recupera la "dimensión sensible", la materialidad de un acontecimiento. Piglia también le otorga a la literatura una función enorme al pensarla como espacio donde, bajo la forma de réplicas y dobles, se puede reponer lo que se ha perdido. Un trabajo de reparación. En El último lector se citan distopías que construyen mundos hostiles en los que habita un tipo de lector subversivo, un rebelde que insiste en el acto de resistencia de la lectura: "Siempre hay una isla donde sobrevive algún lector, 
como si la sociedad no existiera. Un territorio devastado en el que alguien reconstruye el mundo perdido a partir de la lectura de un libro. Mejor sería decir: la creencia en lo que está escrito en un libro permite sostener y reconstruir lo real que se ha perdido" (2005: 152). Robinson Crusoe es el ejemplo de un sujeto perseverante que materializa en una réplica lo que existe en un mundo lejano. Hace tiempo, escribí: "La literatura maneja dobles o sustitutos que no compensan pero constituyen, no obstante, las verdades a alcanzar o los objetos deseados. Las réplicas y los dobles, sin el aspecto siniestro que veía Freud, abren la esperanza de la restitución, o mejor, devuelven los objetos a la vida. Podría decirse que la práctica literaria realiza el trabajo de duelo" (Rodríguez Pérsico 2007). El mundo literario de Piglia está atiborrado de dobles y de réplicas de distintos tipos y de diferentes niveles. El original se ha perdido para siempre pero ya no tiene importancia porque lo imprescindible para la vida se halla en el poder de la ficción.

\section{BIBLIOGRAFÍA}

Badiou Alain y Nicolás Truong, Elogio del amor, Buenos Aires, Paidós, 2012.

Brecht Bertold, "Las cinco dificultades para escribir la verdad", El Viejo Topo, 16 de agosto de 2016. Web.

Heidegger Martin, "La doctrina de Platón acerca de la verdad", Eikasia. Revista de Filosofía n 12, extraordinario I, 2007. Web.

Mallarmé Stéphane, CEuvres Complètes, Paris, Gallimard, 1945.

Piglia Ricardo, Respiración artificial, Buenos Aires, Pomaire, 1980.

--- "La loca y el relato del crimen", AA.VV., El cuento policial, Buenos Aires, Centro Editor de América Latina, Capítulo, 1981, p. 98-105.

--- Critica y ficción, Buenos Aires, Siglo veinte, 1990.

--- Plata quemada, Buenos Aires, Planeta, 2000.

--- El último lector, Buenos Aires, Anagrama, 2005.

--- “Una propuesta para el próximo milenio", Antología personal, Buenos Aires, Fondo de Cultura Económica, 2014, p. 119-128.

--- (2015a), Los diarios de Emilio Renzi. Años de formación, Buenos Aires, Anagrama.

--- (2015b), La forma inicial, Buenos Aires, Eterna Cadencia.

--- Los diarios de Emilio Renzi. Los años felices, Buenos Aires, Anagrama, 2016.

--- Los diarios de Emilio Renzi. Un día en la vida, Buenos Aires, Anagrama, 2017.

Ricoeur Paul, La memoria, la historia, el olvido, Buenos Aires, Fondo de Cultura Económica, 2004.

Rodríguez Pérsico Adriana, “La práctica literaria, entre la pérdida y la restauración”, Rose Corral (ed.), Juan José Saer y Ricardo Piglia: Entre la ficción y la reflexión, México, Colegio de México, 2007, p. 137-148. 
--- “Los diarios de Emilio Renzi o el pudor autobiográfico", Revista Zama n9, Instituto de Literatura Hispanoamericana, Universidad de Buenos Aires, 2017, p. 59-69.

\section{NOTAS}

1. Hay en Piglia una ética de la resistencia. Sus héroes no son los que triunfan sino los que resisten, ya sea que sobrevivan o mueran en su accionar. En Plata quemada, Renzi aparece como un nostálgico de la aventura y, quizás por esta razón, arma una historia que toma partido por los "héroes" que son criminales y drogadictos. El periodista piensa en la voluntad de morir que muestran los delincuentes y compara sus acciones con las conductas policiales: "Pero la diferencia es abismal, es la misma diferencia que existe entre luchar para vencer y luchar para no ser derrotado" (Piglia 2000: 176); "No esperan nada, sólo quieren resistir" (175). Resistir es negarse a entrar en la lógica del Otro -la ley, el padre, las costumbres, el código de la lengua-.

2. La versión original aparece en Margens/márgenes. Revista de cultura $\mathrm{n}^{\circ} 2$, San Pablo, octubre de 2001. Citamos por la versión incluida en Antología personal.

3. Dice Heidegger: "Y porque para los griegos, desde un principio, la ocultación prevalece como un esconderse a sí misma la esencia del Ser y, por consiguiente, también determina al ente en su presencia y accesibilidad ("verdad"), es por lo que la palabra de los griegos, para lo que los romanos llaman "veritas" y nosotros los alemanes "Wahrheit", se distingue por la alfa privativa de su formación, a-léetheia. Verdad significa primariamente lo arrancado con lucha a la ocultación en que yacía. De modo que verdad es ese arrancar con lucha y siempre en la forma de un desentrañar. La ocultación por lo demás puede ser de diversos modos; a saber: encierro, preservación, embozo, encubrimiento, velación, disimulación. Y puesto que, conforme a la "alegoría” platónica, lo desoculto máximo tiene que ser arrancado con lucha a una baja y obstinada disimulación, es por lo que también el desplazamiento de la caverna al aire libre bajo la luz diurna es una lucha a vida o muerte" (2007: 288-289).

4. En Respiración artificial, Arocena, el censor, lee una carta de Angélica Inés Echevarne al intendente en la que registra, como si fuera una antena, escenas de torturas y crematorios: "Yo vi las fotografías: mataban a los judíos con alambre de enfardar. Los hornos crematorios están en Belén, Palestina. Al Norte, bien al Norte, en Belén, provincia de Catamarca" (1980: 99). Quiere ser nombrada Cantora oficial, como la protagonista del cuento de Kafka "Josefina la cantora o el pueblo de los ratones". El discurso usa la coincidencia nominal para confundir tiempos y acontecimientos. En 1976, once militantes son fusilados y hay otros cuatro desaparecidos en el episodio que se conoce como la "masacre de Margarita Belén" (provincia del Chaco). En La ciudad ausente, la máquina, la mujer, la loca argentina, todas ellas personajes literarios e históricos portadores de nombres propios o anónimos tienen la tarea de ser testigos, contar, cantar. La máquina funciona a la manera de una Casandra que ve, predice y enuncia con códigos propios necesidad de desciframiento- la verdad.

5. El saber de la lingüística también es político. Piglia considera a Chomsky el mayor crítico de la política actual. "Un lingüista es por supuesto el que mejor percibe el escenario verbal de la tergiversación, la inversión, el cambio de sentido, la manipulación y la construcción de la realidad que definen el mundo moderno" (2014 :126). 


\section{RESÚMENES}

En Los diarios de Emilio Renzi, Ricardo Piglia pone en marcha "una poética de la elipsis y la distancia". El uso del procedimiento que los formalistas rusos llamaron ostranenie da origen en Piglia a un tono bajo, que huye de cualquier estridencia. Lo que aparece como pudor autobiográfico en los diarios surge en otros textos como una clave poética fundamental que consiste en desplazar el sujeto de la enunciación para poner en el otro la expresión del dolor propio. "La verdad tiene la estructura de una ficción donde otro habla. Hay que hacer en el lenguaje un lugar para que el otro pueda hablar", dice Piglia. Desde su punto de vista, la literatura es un espacio donde la verdad puede ser dicha. El artículo analiza la concepción de verdad en algunos textos y la relación que ésta mantiene con la literatura.

Dans Los diarios de Emilio Renzi, Ricardo Piglia donne forme à "une poétique de l'ellipse et de la distance". L'utilisation du procédé que les formalistes russes ont appelé ostranenie donne lieu chez lui à un ton qui évite toute note stridente. Ce qui apparaît comme de la pudeur autobiographique dans les journaux est présent dans d'autres textes comme une clé poétique fondamentale qui consiste à déplacer le sujet de l'énonciation pour mettre dans une autre bouche l'expression de la propre douleur. "La vérité a la structure d'une fiction où un autre parle. Dans la langue, il faut faire une place pour que l'autre puisse parler", explique Piglia. De son point de vue, la littérature est un espace où l'on peut dire la vérité. L'article analyse la conception de la vérité dans certains textes et la relation qu'elle entretient avec la littérature.

In Los diarios de Emilio Renzi, Ricardo Piglia sets in motion "a poetics of ellipsis and distance". The use of the technique that the Russian formalists called ostranenie originates here a low tone, which avoids shrillness. What appears as autobiographical modesty in the diaries emerges in other texts as a fundamental poetic key that consists of displacing the subject of enunciation to put on other's mouth the expression of one's own pain. "The truth has the structure of a fiction where another person speaks. You have to make a place in the language so that the other can speak", says Piglia. From his point of view, literature is a space where truth can be told. The article analyzes the idea of truth in some texts and the relationship it maintains with literature.

\section{ÍNDICE}

Palabras claves: Piglia, autobiografía, memoria, distanciamiento, verdad

Keywords: Piglia, autobiography, memory, distance, truth

Mots-clés: Piglia, autobiographie, mémoire, distanciation, vérité

\section{AUTOR}

\section{ADRIANA RODRÍGUEZ PÉRSICO}

Universidad de Buenos Aires. CONICET

adripers51@yahoo.com.ar 